\title{
Endoscopic third ventriculostomy is a safe and effective procedure for the treatment of Blake's pouch cyst
}

\author{
Terceiroventriculostomia endoscópica é um procedimento \\ efetivo e seguro para o tratamento dos cistos da bolsa de Blake
}

Carlos Vicente Brusius', Sergio Cavalheiro²

\begin{abstract}
Objective: Blake's pouch cyst (BPC) is a midline cystic malformation of the posterior fossa, within Dandy-Walker's complex (DWC), often associated with hydrocephalus. Endoscopic third ventriculostomy (ETV) has been an alternative to conventional methods for BPC treatment. This study aimed at reporting our experience with ETV in a series of patients with BPC. Methods: Of 33 patients diagnosed with midline posterior fossa cyst, 26 met the protocol criteria for DWC, and eight subjects with BPC were selected (aged one month to two years old). All cases were treated with ETV. Results: Five patients were male; and three were prenatally diagnosed. They had hydrocephalus and motor deficiencies. Motor assessment at a five-year follow-up yielded normal findings. All patients improved, and only one had residual cognitive dysfunction, despite overall neurological improvement. There were no complications. Conclusions: ETV was a safe and effective procedure, reducing risks and morbidity associated with open surgery and shunt-related problems.
\end{abstract}

Key words: Dandy-Walker syndrome, third ventriculostomy, Blake's pouch cyst, neuroendoscopy, complex hydrocephalus.

RESUMO

Objetivo: O cisto da bolsa de Blake (CBB) é uma malformação cística mediana da fossa posterior, dentro do complexo de Dandy-Walker (CDW), frequentemente associada à hidrocefalia. A terceiroventriculostomia endoscópica (TVE) tem sido considerada uma alternativa aos métodos convencionais de tratamento do CBB. Este estudo teve como objetivo relatar nossa experiência com TVE em uma série de pacientes com CBB. Métodos: Dos 33 pacientes diagnosticados com cisto mediano da fossa posterior, 26 preencheram os critérios do protocolo para CDW, dos quais oito foram selecionados com CBB (idades variando entre um mês a dois anos). Todos os casos foram tratados com TVE. Resultados: Cinco pacientes eram do sexo masculino, três tiveram diagnóstico no pré-natal; e todos apresentavam hidrocefalia e alterações motoras. A avaliação motora após cinco anos apresentou resultados normais. Todos os pacientes melhoraram, e apenas um apresentou um leve déficit cognitivo, apesar da melhora neurológica geral. Não houve complicações. Conclusões: A TVE foi um procedimento seguro e eficaz, reduzindo riscos e morbidade associados à cirurgia aberta e a problemas relacionados aos shunts.

Palavras-Chave: síndrome de Dandy-Walker, terceiroventriculostomia, cisto da bolsa de Blake, neuroendoscopia, hidrocefalia complexa.

Cystic malformations of the posterior fossa are often revealed by neuroimaging studies in the brains of children. This abnormal amount of cerebrospinal fluid accumulated in the posterior fossa is classified in the spectrum termed the Dandy-Walker complex (DWC) or as arachnoid cysts ${ }^{1-7}$. The DWC encompasses the following anomalies: DW malformation ${ }^{1-5}$, DW variant ${ }^{8}$, and mega-cisterna magna ${ }^{8}$.
Tortori-Donati et al. ${ }^{9}$ have recently suggested that persistent Blake's pouch cyst (BPC) is a separate entity within the $\mathrm{DWC}^{6}$.

$\mathrm{BPC}$ consists of posterior ballooning of the superior medullary velum into the cisterna magna. All malformations considered part of the DWC are distinct, but overlapping developmental anomalies with different degrees of malformation. Such disorders affect the medullary vela, the cerebellar

\footnotetext{
'MD, Master's candidate, Graduate Program in Neurosurgery, Escola Paulista de Medicina, Universidade Federal de São Paulo (EPM-Unifesp), São Paulo, SP; Staff neurosurgeon at Hospital da Criança Santo Antônio, Santa Casa de Misericórdia de Porto Alegre and Hospital Moinhos de Vento, Porto Alegre RS, Brazil; ${ }^{2}$ MD, MSc, PhD, Thesis adviser, Head Professor of Neurosurgery, Department of Neurology and Neurosurgery, EPM-Unifesp, Coordinator, Graduate Program in Neurosurgery, EPM-Unifesp, São Paulo SP, Brazil.

Correspondence: Carlos Brusius; Rua Padre Chagas 185 / 908; 90570-080 Porto Alegre RS - Brasil; E-mail: cbrusius@uol.com.br

Support: This study is part of the lead author's master thesis project. Approved by São Paulo Federal University (Unifesp) Research Ethics Committee with protocol number 1347/10

Conflict of interest: There is no conflict of interest to declare.

Received 18 September 2012; Received in final form 28 January 2013; Accepted 04 February 2013.
} 
hemispheres and vermis, the choroid plexus of the fourth ventricle, the subarachnoid cisterns of the posterior fossa, and the surrounding meningeal structures ${ }^{10-12}$.

Considering clinical aspects, DWC cysts are often related to other developmental anomalies and very commonly involve hydrocephalus, with greater motor rather than cognitive impairment in most cases $^{8,9,13}$. To many authors ${ }^{9,14-17}$, treatment options for patients with BPC and hydrocephalus range from marsupialization of the posterior fossa cyst to shunting of the cyst or ventricle; however, all of them have reported complications and high morbidity associated with open surgery and shunt-related problems. Endoscopic third ventriculostomy (ETV) has been effective in the treatment of obstructive hydrocephalus, with some advantages over the conventional approaches ${ }^{18-20}$. Thus, in line with the current trend of using minimally invasive procedures in neurosurgery, the ETV has been considered a good alternative for BPC treatment. The purpose of this study was to report an experience with ETV in a series of patients with BPC.

\section{METHODS}

Patients aged $<18$ years diagnosed with midline cystic malformations of the posterior fossa, within the DWC, were enrolled between March 1996 and March 2005 at Hospital São Paulo, the neurosurgery service of the Federal University of São Paulo School of Medicine (EPM-Unifesp), in São Paulo, Brazil. The study was approved by the Unifesp Research Ethics Committee, and was conducted in accordance with the provisions of the Declaration of Helsinki. The written informed consent was obtained from all patients' parents or legal guardians.

Initially, the sample included 33 children diagnosed with midline posterior fossa cyst, aged between 1 month and 2 years. Of these, seven patients did not meet the criteria for neurosurgical treatment (individuals in poor clinical condition for surgery or refusal to participate in the research), therefore they were excluded from the study. The diagnosis of BPC was based on transfontanellar ultrasound, computed tomography (CT), cranial magnetic resonance imaging (MRI), fetal MRI (28-week gestation), and defined as midline posterior fossa cyst with a patent cerebral aqueduct and associated with hydrocephalus (Figure). Thus, within a series with 26 cases of DWC, eight patients met the criteria for BPC. All of them were treated with ETV, and were followedup for five years.

The Denver Developmental Screening Test (DDST), which takes into account the four main areas of child development (personal-social, fine motor-adaptive, gross motor, and language), was applied to each patient for motor and cognitive assessments. Cognitive performance was classified as: the child can learn easily and accomplish school tasks adequately; the child learns more slowly than his/her classmates; the child requires special educational assistance; and the child is not able to learn.

ETV procedures were performed under general anesthesia using a rigid 6-mm neuroendoscope with zerodegree lens. Cyst fenestration was performed using a $4 \mathrm{~F}$ Fogarty catheter (Baxter Healthcare Corp., Houston, TX, USA; Edwards Laboratories, Inc., Santa Ana, CA, USA) and complemented with scissors, whenever it was necessary. The procedure was performed with the patient in the supine position and a $30^{\circ}$ head-up tilt, with the head in the neutral position or slightly to the left. A $3 \times 3 \mathrm{~cm}$ area was shaved in the right coronal suture, and a linear skin incision of approximately $4 \mathrm{~cm}$ was made until the periosteum, parallel to and $2 \mathrm{~cm}$ away from the coronal suture. The edges of the incision were separated, and a trepanation was performed at Kocher's point ${ }^{19}$. It is worth mentioning that in the newborn, the bone can be perforated by rotational movements using a 15-blade scalpel, or in diastasis cases of the coronal suture, especially in those of the severe hydrocephalus, when a trepanation is not necessary. Then, the dura mater was opened, followed by hemostasis and a punctiform opening in the arachnoid. The trocar of the endoscope was inserted through the brain parenchyma to the lateral ventricle and maintained for endoscope insertion (Aesculap, Tuttlingen, Germany; Karl Storz, Tuttlingen, Germany). This was positioned in the lateral ventricle to visualize the internal structures, such as Monro's foramen, the thalamostriate vein, and the septum pellucidum, which are intraventricular anatomical landmarks for endoscopic navigation, and for subsequent location of the fornix and the floor of the ventricle. In the presence of hemorrhage during the procedure, irrigation was performed with saline heated to $37^{\circ} \mathrm{C}$.

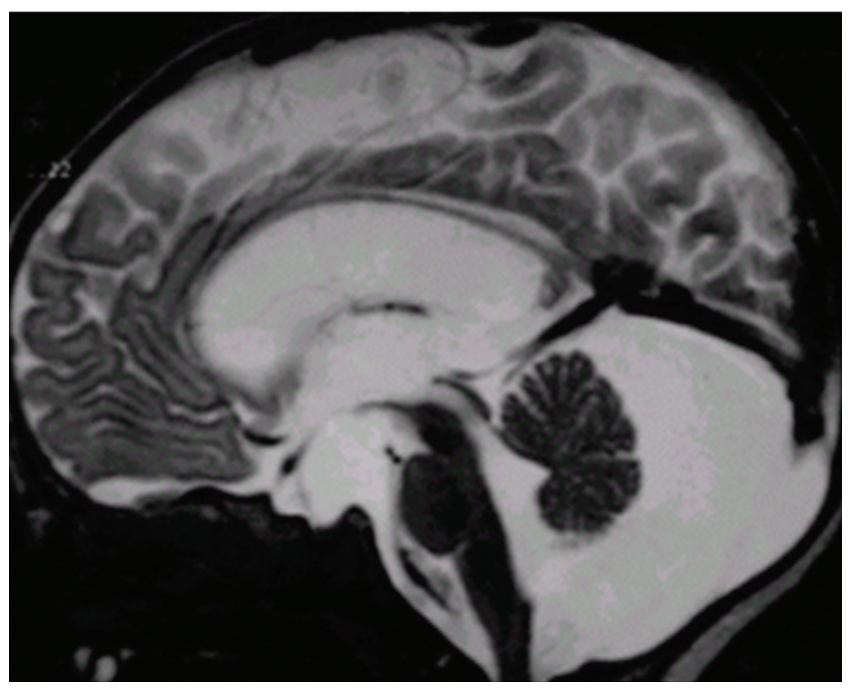

Figure. T2-weighted magnetic resonance imaging of a Blake's pouch cyst (midline posterior fossa cyst with a patent cerebral aqueduct, wide posterior fossa, and hydrocephalus). 


\section{RESULTS}

Of eight patients with BPC considered eligible for this study, five were male and three were female. Their ages were $1,7,26,2,11,9,2$, and 48 months. Three patients were prenatally diagnosed. All of them had hydrocephalus and motor deficiencies, and underwent ETV.

Motor assessment of these patients at a five-year followup yielded normal findings, presenting a ventricular index lower than 0.4. All subjects showed reduction in cyst volume and ventricular diameters. In general, they improved and only one had residual cognitive dysfunction, despite overall neurological improvement. There were no complications in any of the eight cases.

\section{DISCUSSION}

In our case series with 26 midline posterior fossa cysts, they were all classified within the DWC, being eight patients diagnosed with BPC and treated by ETV. In all of the situations, ETV showed reduction in cyst volume and ventricular diameters, allowing the development of cerebellum and cerebellar vermis.

BPCs are considered an embryological regression failure of Blake's pouch (originating from the rudimentary tela chorioidea of the fourth ventricle) caused by an imperforate foramen of Magendie ${ }^{9,21}$, and leading to dilatation of the superior medullary velum towards the cisterna magna ${ }^{9,22-25}$. Another significant aspect is that the foramen of Luschka is characterized by later opening during embryological development as compared with that of Magendie. Hence, the fourth ventricle will dilate simultaneously with the supratentorial ones up to the opening of the foramen of Luschka when there is imperforation of Magendie's foramen. As a result, there is an imbalanced cerebrospinal fluid flow between the ventricles and the cisterns ${ }^{8,14,21,25-28}$. Hence, with temporary imperforation of Magendie's foramen, the ventricles remain dilated. Furthermore, based on the theory of BPC, the cerebellar hemispheres and vermis will be subjected to a certain degree of compression and remain underdeveloped. Finally, it has been suggested that BPC and mega-cisterna magna have different origins from DW malformation and variant; whereas the former is now considered to derive from a formative defect of the posterior membranous area, and the latter originates from an issue of the anterior membranous area ${ }^{9,14}$.

Cyst marsupialization is often proposed in an attempt to reconstruct a new Magendie's foramen and thus establish a new pathway for cerebrospinal fluid. If this procedure achieves its purpose, it may reduce the pouch, enabling reexpansion of the cerebellar hemispheres and vermis and, consequently, relieving hydrocephalus ${ }^{29-31}$.
According to Tortori-Donati et al. ${ }^{9}$ and Cornips et al. ${ }^{13}$, when the lateral ventricles (or cyst) undergo shunting, they return to normal size, with consequent collapse of the cystic fourth ventricle. Conti et al. ${ }^{17}$ found that cyst fenestration alone was not efficient as a treatment of cases in which there was associated syringomyelia. The solution was to place a ventriculoperitoneal shunt. In their study, the authors considered that ETV could be an alternative therapeutic solution.

The arachnoid membrane is usually very thin in the absence of inflammatory processes. T2-weighted fast imaging employing steady-state acquisition (FIESTA ${ }^{\circledR}$, General Electric Company; CISS, Siemens) MRI images are required for this differentiation; however, membranes that are tightly adhered to the cerebellum are difficult to differentiate. The most important points for diagnosis are cerebral aqueduct patency in continuity with the posterior fossa cyst and absence of cerebellar malformations of the posterior fossa. This diagnosis can be suspected by ultrasound during the fetal period. CT may also be helpful in the diagnosis, but it should be avoided in this age group.

Regarding clinical status, motor function is more greatly impaired. The children are unable to walk, but their intelligence is within the normal range. This aspect differentiates BPCs from simple posterior fossa arachnoid cysts, because they do not often show such symptoms. Immediate improvement after treatment leads us to believe that the motor status occurs only due to compression of the brain stem and cerebellum, and that after normalization of the blood pressure by ETV, symptoms disappear in most patients.

Ventricular indices, as well as volume, are not suitable criteria for monitoring these patients, because, as described in the literature, cystic or ventricular cavities do not always decrease in size. The results in our patients were assessed after evident improvement of motor function and normalization of head circumference.

In our series, ETV was used in patients with symptomatic $\mathrm{BPC}$ in an attempt to avoid the risks and morbidity associated with open surgery and issues related to shunt valves, such as occlusion and overdrainage. Surgical treatment was based only on the opening of the third ventricle floor and Liliequist's membrane, which in this age group is not adhered to the tuber cinereum ${ }^{13}$. The procedure was effective in all cases, with reductions in cyst volume and fourth ventricular diameter as well as supratentorial ventricular diameter, allowing the development of cerebellum and cerebellar vermis.

The results were indeed excellent in this series, since we always perform a small frontal craniotomy in infants in order to tightly close the dura mater. Moreover, we do not use any substitutes for dura mater or any glue. We are, therefore, dealing with an obstructive hydrocephalus, and neuroendoscopy is the technique that provides the best results for this type of disease. Furthermore, ETV is an established, minimally invasive procedure that decreases patient's risk, shortens length of stay, 
and enables faster and more consistent postoperative recovery $^{18,19}$, and its benefits have been shown to outweigh costs ${ }^{20}$.

It is worth noting the relative rarity of the cystic malformations diagnosis within the DWC, which makes it difficult to gather a larger series of patients to study. Thus, the remaining 26 DWC cases are soon to be described. Additionally, we are currently working on a classification system for midline posterior fossa cysts, dividing lesions into three types, which is also soon to be fully described.

In conclusion, ETV was a safe and effective treatment for $\mathrm{BPC}$ in this series of patients, reducing risks and morbidity associated with open surgery and shunt-related problems.

\section{References}

1. Arai H, Sato K. Posterior fossa cysts: clinical, neuroradiological and surgical features. Childs Nerv Syst 1991;7:156-164.

2. Dandy WE. Diagnosis and treatment of hydrocephalus due to occlusion of the foramina of Magendie and Luschka. Surge Gynecol Obstet 1921;32:112-124

3. Portugal JR, Brock M. On the pathogenesis of the Dandy-WalkerBrodal syndrome. Zentralbl Neurochir 1962;23:80-97.

4. Dandy WE, Blackfan KD. Internal hydrocephalus: an experimental, clinical, and pathological study. Am J Dis Child 1914;8:406-482.

5. Al-Gazali LI, Raziq AA, Al-Shater W, Shahzadi R, Azhar N. Meckel syndrome and Dandy Walker malformation. Clin Dysmorphol 1996;5:73-76.

6. Calabro F, Arcuri T, Jinkins JR. Blake's pouch cyst: an entity within the Dandy-Walker continuum. Neuroradiology 2000;42:290-295.

7. D'Agostino AN, Kernohan JW, Brown JR. The Dandy-Walker syndrome. J Neuropathol Exp Neurol 1963;22:450-470.

8. Strand RD, Barnes PD, Poussaint TY, Estroff JA, Burrows PE. Cystic retrocerebellar malformations: unification of the DandyWalker complex and the Blake's pouch cyst. Pediatr Radiol 1993; 23:258-260.

9. Tortori-Donati P, Fondelli MP, Rossi A, Carini S. Cystic malformations of the posterior cranial fossa originating from a defect of the posterior membranous area. Mega cisterna magna and persisting Blake's pouch: two separate entities. Childs Nerv Syst 1996; 12:303-308.

10. Bertucci E, Gindes L, Mazza V, Re C, Lerner-Geva L, Achiron R. Vermian biometric parameters in the normal and abnormal fetal posterior fossa: three-dimensional sonographic study. J Ultrasound Med 2011;30:1403-1410.

11. Bhadelia RA, Bogdan AR, Kaplan RF, Wolpert SM. Cerebrospinal fluid pulsation amplitude and its quantitative relationship to cerebral blood flow pulsations: a phase-contrast MR flow imaging study. Neuroradiology 1997;39:258-264.

12. Brown JR. Congenital malformations of the brain and skull. In: Vinken PJ, Bruyn GW (eds). Handbook of clinical neurology. Amsterdam: Elsevier North-Holland Publishing Co.; 1977.

13. Cornips EM, Overvliet GM, Weber JW, et al. The clinical spectrum of Blake's pouch cyst: report of six illustrative cases. Childs Nerv Syst 2010;26:1057-1064.

14. Nelson MD Jr., Maher K, Gilles FH. A different approach to cysts of the posterior fossa. Pediatr Radiol 2004;34:720-732.

15. Buxton N, Vloeberghs M, Punt J. Liliequist's membrane in minimally invasive endoscopic neurosurgery. Clin Anat 1998;11:187-190.

16. Cinalli G, Spennato P, Del Basso ML, Buonocore MC. Hydrocephalus and the Dandy-Walker malformation. In: Cinalli G(Ed). Pediatric hydrocephalus. Milan: Springer; 2004. p. 259-277.
17. Conti C, Lunardi P, Bozzao A, Liccardo G, Fraioli B. Syringomyelia associated with hydrocephalus and Blake's pouch cyst: case report. Spine 2003;28:279-283.

18. Cinalli G, Salazar C, Mallucci C, Yada JZ, Zerah M, Sainte-Rose C. The role of endoscopic third ventriculostomy in the management of shunt malfunction. Neurosurgery 1998;43:1323-1327.

19. Hopf NJ, Grunet P, Fries G, Resch KD, Perneczky A. Endoscopic third ventriculostomy: outcome analysis of 100 consecutive procedures. Neurosurgery 1999;44:795-804.

20. Barlow P, Ching HS. An economic argument in favour of endoscopic third ventriculostomy as a treatment for obstructive hydrocephalus. Minim Invasive Neurosurg 1997;40:37-39.

21. Barkovich AJ, Kjos BO, Norman D, Edwards MS. Revised classification of posterior fossa cysts and cystlike malformations based on the results of multiplanar MR imaging. AJR Am J Roentgenol 1989;153:1289-1300.

22. Coleman CC, Troland CE. Congenital atresia of the foramina of Luschka and Magendie with report of two cases of surgical cure. J Neurosurg 1948;5:84-88.

23. Di Rocco C. Arachnoid cysts. In:Youmans JR (ed). Neurological surgery Philadelphia: WB Saunders Company; 1998. p. 3289-3299.

24. Di Trapani G, Di Rocco C, Pocchiari M, Abbamondi AL. Arachnoid cysts in children: ultrastructural findings. Acta Neuropathol 1981;7:S392-S395.

25. Domingo Z, Peter J. Midline developmental abnormalities of the posterior fossa: correlation of classification with outcome. Pediatr Neurosurg 1996;24:111-118.

26. Brodal A, Hauglie-Hanssen E. Congenital hydrocephalus with defective development of the cerebellar vermis (Dandy-Walker syndrome) clinical and anatomical findings in two cases with particular reference to the so-called atresia of the foramina of Magendie and Luschka. $J$ Neurol Neurosurg Psychiatry 1959;22:99-108.

27. Siebert JR. A pathological approach to anomalies of the posterior fossa. Birth Defects Res Clin Mol Teratol 2006;76:674-684.

28. Zalel Y, Gilboa Y, Gabis L, et al. Rotation of the vermis as a cause of enlarged cisterna magna on prenatal imaging. Ultrasound Obstet Gynecol 2006;27:490-493.

29. Cornips EM, Overvliet GM, Weber JW, et al. The clinical spectrum of Blake's pouch cyst: report of six illustrative cases. Childs Nerv Syst 2010;26:1057-1064.

30. Duffner F, Freudenstein D, Wacker A, Straub-Duffner S, Grote EH. [75 years after Dandy, Fay and Mixter--looking back on the history of neuroendoscopy]. Zentralbl Neurochir 1998;59:121-128.

31. Warf BC, Dewan M, Mugamba J. Management of Dandy-Walker complex-associated infant hydrocephalus by combined endoscopic third ventriculostomy and choroid plexus cauterization. J Neurosurg Pediatr 2011;8:377-383. 